\title{
Bowel function in adults who have sustained spinal cord injury in childhood
}

\author{
M Kannisto and R Rintala \\ Children's Hospital, University of Helsinki, Finland
}

The impact of neuropathic bowel dysfunction on bowel habits was studied in 35 adult spinal cord injury (SCI) patients, who had sustained their injury in childhood. The methods used in the study were clinical interview and examination, quantitative scoring of bowel function (BCS) and estimation of bowel transit time with radiopaque markers. Thirty five healthy subjects without previous anorectal disease or surgery and with similar age and sex distribution as the patients served as controls. Most of the SCI patients were content with their bowel function. Nine $(26 \%)$ out of 35 of the SCI patients were completely satisfied with their bowel function and reported no limitations in social life. The majority (69\%) of the patients considered their bowel function to be significantly altered, causing only mild problems in their social life. Two of the patients had major problems of bowel function, which caused severe limitations in their social life. The majority $(77 \%)$ of the patients declared that they had a low frequency of bowel evacuation. Eight out of 35 patients were using laxatives to promote bowel emptying. The quantitative BCS of the patients was significantly lower than that of the controls $(P<0.001)$. Moreover, there was a significant difference between the scores of patients with complete high (C2-T6) and complete low (T7-S4-5) lesions. The difference between the BCS and overall satisfaction with bowel function can be explained by good habilitation to SCI and by the prolonged transit times which enables relatively rare and controlled bowel movements and firm consistency of stools.

Keywords: colon; spinal cord injuries; spinal cord injuries in childhood; bowel function; neuropathic constipation; neuropathic bowel

\section{Introduction}

Bowel function is known to be severely altered after spinal cord injury (SCI). ${ }^{1}$ Neuropathic bowel dysfunction in SCI patients is manifested by prolonged oroanal transit time, diminished faecal water content and a reduced frequency of defecation. ${ }^{2}$ Faecal incontinence ensues through loss of anorectal sensibility and loss of inhibitory regulation of the anorectum and the left colon by upper cerebral inputs and by lack of ability to voluntarily contract the external anal sphincter. ${ }^{1,3,4}$ Faecal incontinence and chronic constipation may have a significant impact on the quality of life and may cause a secondary morbidity in SCI patients. ${ }^{5,6}$

In the rehabilitation phase a bowel retraining programme is commonly introduced to SCI patients with the aim of achieving continence and regularity of defecation. ${ }^{7}$ Although rehabilitation programmes are often successful, the long term dysfunctions are common and may be difficult to treat. ${ }^{8}$

To find out the long term outcome in terms of bowel function and faecal continence we interviewed and

Correspondence: M Kannisto, Fysiatrian yksikkö, Peijas Hospital, Sairaalakatu 1, Vantaa 01400, Finland examined 35 adult SCI patients who had sustained spinal cord injury in childhood.

\section{Materials and methods}

\section{Patients}

Ten females and 25 males who had sustained SCI in childhood participated in this study.

The names of the subjects were collected from the central register of the Finnish National Organisation for Disabled People. Thirty-five healthy persons with similar age and sex distribution as the patients were used as controls. The controls had had no previous anorectal surgery or known colorectal diseases.

At the time of the study the median age of the patients was 31 years (range 18.1-63). The median time period from the injury was 19 years (range 1.5-57). The median age at injury was 12.9 years (range from birth to 17.1 years). All the patients were interviewed and clinically examined. The spinal lesions were classified according to the level and the completeness of the injury according to the standards of neurological classification of spinal cord injury patients. ${ }^{9}$ 
Assessment of bowel function

Patients' subjective opinions concerning their actual bowel function were recorded. The patients evaluated their bowel function on a scale ranging from 1 to 3 . Three points meant satisfaction with present bowel function. Patients with two points experienced some difficulties and had minor social limitations due to bowel dysfunction. Patients with one point had severe difficulties and had marked social limitations.

The objective bowel continence of the patients and controls was evaluated with a quantitative scoring method $^{10,11}$ (Table 1).

The bowel continence scores (BCS) were calculated from the questionnaires completed by the patients and the 35 healthy controls.

The existence of constipation was verified with radiopaque markers. The patients were asked to ingest 20 radiopaque markers (Sitzmarks TM, Lafayette Pharmacal Inc, Fort Worth, Texas) 4 days before abdominal radiographs were taken. Constipation was determined from the location and the extent of the elimination of the markers. Transit time was considered to be prolonged if 10 or more markers were retained over the period of $96 \mathrm{~h}$.

\section{Statistical methods}

The Wilcoxon matched pairs test was used to analyse the differences between the BCS of the study group and the healthy controls. One-way analysis of variance (ANOVA) was used to examine the BCS in different neurological lesion levels.

\section{Results}

Twenty four patients of the study group had complete paraplegia. Three patients had incomplete paraplegia, three patients were tetraplegic and five patients had incomplete tetraplegia (Table 2).

Nine of the patients were fully satisfied with their bowel function and reported no limitations in their everyday social life. The majority of the patients $(24 / 35)$ considered their bowel function to be significantly altered but the altered bowel function caused only minor social problems. Two of the subjects had major difficulties in bowel function which caused severe social disability.

The continence scores of the patients differed significantly from those of the healthy controls. All the controls had good faecal continence. Only minor and occasional problems in bowel function, such as constipation, slight smearing and difficulties in holding back flatus were reported by the controls. The median score of the controls was 14/14, SD 1.71 and range 10-14. In the SCI group the median score was $8 / 14$, SD 2.65 and range 3-14. The difference between the scores of controls and SCI-group was highly significant, $P<0.001$.

The patients with complete low lesions (T7-S4-5) had significantly better scores (mean 8.3, SD 2.15) than
Table 1 Scoring method for clinical evaluation of continence

\begin{tabular}{|c|c|c|c|}
\hline \multicolumn{2}{|c|}{ Frequency of defecation } & $\begin{array}{l}\text { Normal }(1-2 / \text { day }) \\
\text { Often }(3-5 / \text { day }) \\
\text { Very often }\end{array}$ & $\begin{array}{l}2 \\
1 \\
0\end{array}$ \\
\hline \multicolumn{2}{|c|}{ Rectal sensation } & $\begin{array}{l}\text { Always } \\
\text { Defective } \\
\text { Missing }\end{array}$ & $\begin{array}{l}2 \\
1 \\
0\end{array}$ \\
\hline \multicolumn{2}{|l|}{ Soiling } & $\begin{array}{l}\text { No } \\
\text { Stress/diarrhoea } \\
\text { Constant }\end{array}$ & $\begin{array}{l}2 \\
1 \\
0\end{array}$ \\
\hline \multicolumn{2}{|c|}{$\begin{array}{l}\text { Ability to hold back } \\
\text { defecation }\end{array}$} & $\begin{array}{l}\text { Minutes } \\
\text { Seconds } \\
\text { Missing }\end{array}$ & $\begin{array}{l}2 \\
1 \\
0\end{array}$ \\
\hline \multicolumn{2}{|c|}{ Faecal consistency } & $\begin{array}{l}\text { Normal } \\
\text { Loose } \\
\text { Liquid }\end{array}$ & $\begin{array}{l}2 \\
1 \\
0\end{array}$ \\
\hline \multicolumn{2}{|c|}{$\begin{array}{l}\text { Discrimination between } \\
\text { formed, loose or gaseous } \\
\text { stools }\end{array}$} & $\begin{array}{l}\text { Normal } \\
\text { Defective } \\
\text { Missing }\end{array}$ & $\begin{array}{l}2 \\
1 \\
0\end{array}$ \\
\hline \multicolumn{2}{|c|}{ Need for therapy } & $\begin{array}{l}\text { No } \\
\text { Occasionally } \\
\text { Always }\end{array}$ & $\begin{array}{r}2 \\
1 \\
0 \\
(\max .14)\end{array}$ \\
\hline \multicolumn{4}{|c|}{$\begin{array}{l}\text { Scoring } \\
\text { 14: normal bowel habits } \\
\text { 13-10: good (social continence, few limi } \\
\text { life) } \\
\text { 5-9: fair (marked limitations in social life) } \\
\text { 0-4: poor (total incontinence) }\end{array}$} \\
\hline & & Complete I & Incomplete \\
\hline Tetraplegia & $\begin{array}{l}\text { High }(\mathrm{C} 1-5) \\
\text { Intermediate } \\
\text { Low }(\mathrm{C} 7-\mathrm{T} 1)\end{array}$ & $\begin{array}{l}2 \\
1\end{array}$ & $\begin{array}{l}3 \\
2\end{array}$ \\
\hline Paraplegia & $\begin{array}{l}\text { High (T1-6) } \\
\text { Low (T7) }\end{array}$ & $\begin{array}{r}7 \\
17\end{array}$ & $\begin{array}{l}1 \\
2\end{array}$ \\
\hline Total & & 27 & 8 \\
\hline
\end{tabular}

the patients with complete high lesions (C2-T7) (mean 6.5 , SD 1.37, ANOVA $F=5.602, P<0.05$ ).

Twenty-seven of the 35 patients $(77 \%)$ reported a low frequency of bowel evacuation (2-3/week).

Catharctics, bulk laxatives, enemas or suppositories were used regularly by eight $(23 \%)$ out of 35 patients. All of them emptied bowels two to three times a week. Two patients $(6 \%)$ suffered from daily soiling, 23 $(66 \%)$ soiled sometimes and ten $(29 \%)$ reported no soiling. However, all the patients had soiling in special circumstances like during diarrhoeic episodes.

The daily soiling of the two patients was caused by 
overflow incontinence. Both of them were severely constipated.

All the subjects declared that they usually had firm or semifirm stool consistency. Loose stools or diarrhoea was not reported to occur regularly in any of the cases. The colonic transit was markedly prolonged in 19 $(54 \%)$ of our 35 subjects.

Complications related to faecal impaction were rare. One of the patients had had a major abdominal emergency because of colonic perforation associated with faecal impaction. In this case the positive Kehr sign and increased spasticity led to diagnostic radiography, laparotomy and temporary colostomy.

\section{Discussion}

The majority of the studied adult SCI patients were content or had only minor problems in the bowel function. This result is in contrast with the low bowel continence scores. A possible explanation for the relative well-being of the SCI-patients is the low colonic transit time..$^{2,12,13}$

In the present study, all of the 19 patients with a significantly prolonged transit time had the remaining radiopaque markers in the left colon or rectosigmoid. This is in correlation with previous findings. ${ }^{12,13}$ The prolonged transit time makes a patient less prone to soiling by reducing the frequency of bowel emptying and the water content of faeces. On the other hand, the SCI patients in the present study were probably well adapted to their condition because they were injured in childhood.

Eight subjects were using medication or enemas for bowel emptying. These patients wanted to control the time of bowel emptying. The small number of patients using medication can also be interpreted as a sign of good bowel habilitation. The majority of the SCI patients in the study group preferred to use dietary means rather than medication in bowel management.

Two patients had severe constipation and overflow incontinence. These patients might benefit from new treatment modalities for faecal incontinence, such as enema incontinence catheter ${ }^{14}$ or antegrade continence enema. ${ }^{15}$ Undiagnosed abdominal emergencies are considered to account for $10 \%$ of all fatalities among SCI patients. ${ }^{8}$ In this study only one patient had such a complication. In this case the colonic perforation caused by faecal impaction led to the necessity for a temporary colostomy. The colonic continuity was restored, although a permanent colostomy has been reported to alleviate abdominal distention, faecal incontinence and to simplify bowel care. ${ }^{16}$

\section{Conclusions}

The present study shows that the majority of adult patients who have sustained SCI during childhood are well adapted to their bowel function. Despite the lack of voluntary bowel control which was clearly visualised by low BCS when compared to those of healthy subjects, most patients experience no or only minor problems in social life. Although slow colonic transit time is advantageous in patients with SCI, severe constipation associated with overflow incontinence was the main cause of bowel function related social problems.

\section{References}

1 Longo W, Ballantyne G, Modlin I. The colon, anorectum, and spinal cord patient. A review of the functional alterations of the denervated hindgut. Dis Col Rectum 1989; 32: 261-267.

2 Binnie R, Smith A, Creasey G, Edmont P. Constipation associated with chronic spinal cord injury: the effect of pelvic parasympathetic stimulation by the Brindley stimulator. Paraplegia 1991; 29: 463-469.

3 Meshkinpour H, Nowroozi F, Glick M. Colonic compliance in patients with spinal cord injury. Arch Phys Med Rehabil 1983; 64: 111-112.

4 Connell A, Frankel H, Guttmann L. The motility of the pelvic colon following complete lesions of the spinal cord. Paraplegia 1963; 1 : 98-115.

5 Gore R, Mintzer R, Calenoff L. Gastrointestinal complications of spinal cord injury. Spine 1981; 6: 538-544.

6 Banwell J, Creasey G, Aggarwall A, Mortimer T. Management of the neurogenic bowel in patients with spinal cord injury. Urol Clin N Am 1993; 3: 517-526.

7 Staas W, Lamantia J. Bowel function and control. In: Ruskin A (ed). Current Therapy in Physiatry. WB Saunders Company: Philadelphia, 1984, pp 405-410.

8 Cosman B, Stone J, Perkash I. The gastrointestinal complications of chronic spinal cord injury. J Am Paraplegia Soc 1991; 14: $175-181$.

9 Asia/IMSOP. International Standards for Neurological and Functional Classification of Spinal Cord Injury, Revised 1992. American Spinal Cord Injury Association: Chicago, 1992.

10 Holschneider A. Electromanometrie des Enddarmes. Urban \& Schwarzenberg: Munich-Wien-Baltimore 1983, pp 213-218.

11 Rintala R, Mildh L, Lindahl H. Fecal continence and quality of life in adult patients with an operated low anorectal malformation. J Pediatr Surg 1992; 27: 982-988.

12 Menardo $G$ et al. Large bowel transit in paraplegic patients. Dis Colon Rectum 1987; 30: 924-928.

13 Nino-Murcia M, Stone J, Chang P, Perkash I. Colonic transit in spinal cord injured patients. Invest Radiol 1990; 25: 109-112.

14 Liptak GS, Revell GM. Management of bowel dysfunction in children with spinal cord disease or injury by means of the enema continence catheter. J Pediatr 1992; 120: 190-4.

15 Malone PS, Ransley PG, Kiely EM. Preliminary report: The antegrade continence enema. The Lancet 1990; 17: 1217-1218.

16 Stone JM, Wolfe VA, Nino-Murcia M, Perkash I. Colostomy as treatment for complications of spinal cord injury. Arch Phys Med Rehabil 1990; 71: 514-8. 